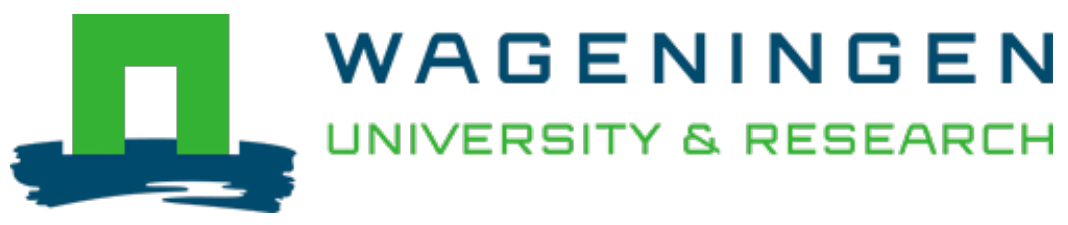

\title{
A slicing mechanism facilitates host entry by plant-pathogenic Phytophthora
}

Nature Microbiology

Bronkhorst, Jochem; Kasteel, Michiel; Veen, Stijn; Clough, Jess M.; Kots, Kiki et al

https://doi.org/10.1038/s41564-021-00919-7

This article is made publicly available in the institutional repository of Wageningen University and Research, under the terms of article $25 \mathrm{fa}$ of the Dutch Copyright Act, also known as the Amendment Taverne. This has been done with explicit consent by the author.

Article $25 \mathrm{fa}$ states that the author of a short scientific work funded either wholly or partially by Dutch public funds is entitled to make that work publicly available for no consideration following a reasonable period of time after the work was first published, provided that clear reference is made to the source of the first publication of the work.

This publication is distributed under The Association of Universities in the Netherlands (VSNU) 'Article $25 \mathrm{fa}$ implementation' project. In this project research outputs of researchers employed by Dutch Universities that comply with the legal requirements of Article $25 \mathrm{fa}$ of the Dutch Copyright Act are distributed online and free of cost or other barriers in institutional repositories. Research outputs are distributed six months after their first online publication in the original published version and with proper attribution to the source of the original publication.

You are permitted to download and use the publication for personal purposes. All rights remain with the author(s) and / or copyright owner(s) of this work. Any use of the publication or parts of it other than authorised under article $25 \mathrm{fa}$ of the Dutch Copyright act is prohibited. Wageningen University \& Research and the author(s) of this publication shall not be held responsible or liable for any damages resulting from your (re)use of this publication.

For questions regarding the public availability of this article please contact openscience.library@,wur.nl 


\title{
A slicing mechanism facilitates host entry by plant-pathogenic Phytophthora
}

\author{
Jochem Bronkhorst ${ }^{1}$, Michiel Kasteel ${ }^{2,3}$, Stijn van Veen ${ }^{1}$, Jess M. Clough ${ }^{1}$, Kiki Kots ${ }^{2,3}$, Jesse Buijs ${ }^{1}$, \\ Jasper van der Gucht', Tijs Ketelaar (iD ${ }^{3}$, Francine Govers ${ }^{\left(D^{2}\right.}$ and Joris Sprakel ${ }^{1}{ }^{凶}$
}

\begin{abstract}
Phytophthora species, classified as oomycetes, are among the most destructive plant pathogens worldwide and pose a substantial threat to food security. Plant pathogens have developed various methods to breach the cuticle and walls of plant cells. For example, plant-pathogenic fungi use a 'brute-force' approach by producing a specialized and fortified invasion organ to generate invasive pressures. Unlike in fungi, the biomechanics of host invasion in oomycetes remains poorly understood. Here, using a combination of surface-deformation imaging, molecular-fracture sensors and modelling, we find that Phytophthora infestans, Phytophthora palmivora and Phytophthora capsici slice through the plant surface to gain entry into host tissues. To distinguish this mode of entry from the brute-force approach of fungi that use appressoria, we name this oomycete entry without appressorium formation 'naifu' invasion. Naifu invasion relies on polarized, non-concentric, force generation onto the surface at an oblique angle, which concentrates stresses at the site of invasion to enable surface breaching. Measurements of surface deformations during invasion of artificial substrates reveal a polarized mechanical geometry that we describe using a mathematical model. We confirm that the same mode of entry is used on real hosts. Naifu invasion uses actin-mediated polarity, surface adherence and turgor generation to enable Phytophthora to invade hosts without requiring specialized organs or vast turgor generation.
\end{abstract}

$\mathrm{P}$ lant pathogens cause huge losses in crop yields with negative impacts on global food security and economy ${ }^{1,2}$. One such pathogen is $P$, infestans, the causal agent of late blight, which is responsible for yield losses estimated at $15-20 \%$ globally $^{3}$. Despite breeding efforts, late blight remains challenging to combat mainly due to the high genetic adaptability of the pathogen ${ }^{4}$. Unlike $P$. infestans, $P$. palmivora and P. capsici have a broad host range and and cause many destructive diseasesfor example, in cacao and oil palm plantations, and in numerous vegetable crops $s^{5,6}$.

Many pathogens must gain forcible entry into their host for successful infection ${ }^{7-11}$. Fungal and oomycete plant pathogens face a substantial challenge as the plant features a protective surface consisting of a cuticle and rigid epidermal cell layers ${ }^{7,9,12}$. The mechanics of host entry have been studied in detail for the fungus Magnaporthe oryzae ${ }^{12-15}$, which employs a brute-force approach: first it undergoes a switch from polar to non-polar growth to establish an appressorium, a specialized and melanin-fortified invasion structure ${ }^{9}$ capable of building high turgor pressure ${ }^{14,15}$ of up to $8 \mathrm{MPa}$. After adhering to the host surface ${ }^{16}$, a penetration peg is ejected in the centre of the adhesion ring to pierce the host surface ${ }^{13}$. Appressorium-mediated invasion in fungi requires both melanins and septins ${ }^{17-19}$. Despite the notion that convergent evolution has provided fungi and oomycetes with similar weaponry to attack and colonize plants ${ }^{8,20,21}$, oomycetes lack septins and melanin, ruling out invasion by brute force. How host entry is achieved by oomycetes remains elusive. Here we unravel the mechanics of host entry of Phytophthora spp. and show how these pathogens exploit hyphal slicing to facilitate host invasion, avoiding the need to form a fortified appressorium.

\section{Results}

We begin by observing that invasion of $P$. infestans into host tissues, represented here by etiolated stems of potato plantlets, consistently occurs by hypha indenting and subsequently invading host tissues at a distinct oblique angle (Fig. 1a and Supplementary Video 1). We determine the average angle of invasion, defined relative to the surface normal (Fig. 1b), as $\theta=36.2 \pm 13.0^{\circ}$. This is in contrast to true fungi, in which a penetration peg emerges from the centre of an adhesion ring and enters the host tissue along the substrate normal ${ }^{13,15}$.

Artificial host mimics. To understand the significance of this observation, we continue our analysis on artificial hosts, where a full mechanical analysis is possible. We use polydimethylsiloxane (PDMS) substrates as a model surface, as it is transparent, hydrophobic (similar to the cuticle), and has elastic moduli in the range of reported leaf stiffnesses ${ }^{22,23}$. We observe that $P$. infestans invasion on these substrates occurs in a manner that is qualitatively similar to that on the natural hosts ${ }^{24}$ (Fig. 1b); zoospores land on the substrate, encyst and develop a germ tube (stage I). The hypha then adheres to the substrate and applies an indentation pressure (stage II). This ultimately leads to surface fracture and host entry (stage III). Furthermore, invasion on these artificial substrates occurs at an oblique angle and without the formation of a distinct appressorium (Fig. $1 \mathrm{~b}$ and Supplementary Video 2). We determine that, for two $P$. infestans strains, $14-3-\mathrm{GFP}^{25}$ and $\mathrm{wt}^{26}$, invasion into artificial substrates peaks at oblique invasion angles $\theta$ of approximately $49 \pm 10^{\circ}$ and that this is independent of substrate stiffness (Fig. 1c-f). The same is observed for two other Phytophthora species, $P$. palmivora $\mathrm{wt}^{27}\left(\theta \approx 41 \pm 11^{\circ}\right.$; Fig. 1g) and P. capsici $\mathrm{wt}^{28}\left(\theta \approx 42 \pm 12^{\circ}\right.$; Fig. $\left.1 \mathrm{~h}\right)$.

\footnotetext{
'Physical Chemistry and Soft Matter, Wageningen University and Research, Wageningen, The Netherlands. ${ }^{2}$ Laboratory of Phytopathology, Wageningen University and Research, Wageningen, The Netherlands. ${ }^{3}$ Laboratory of Cell Biology, Wageningen University and Research, Wageningen, The Netherlands. 凶e-mail: joris.sprakel@wur.nl
} 
a

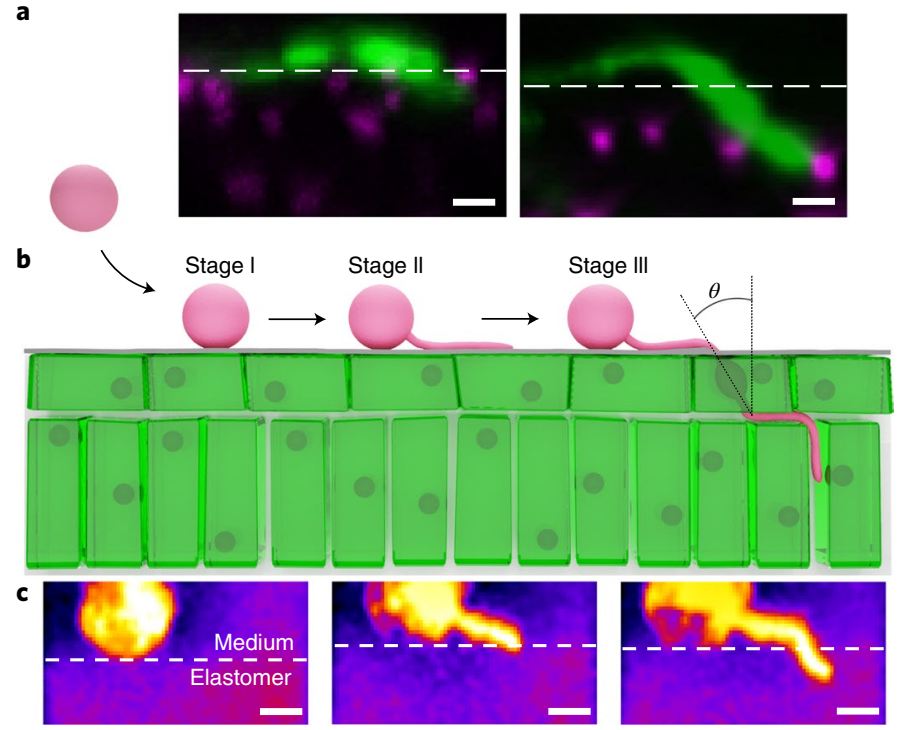

d

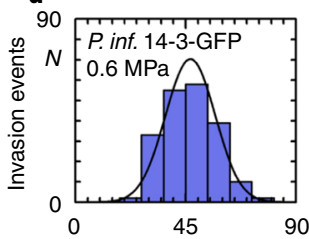

f
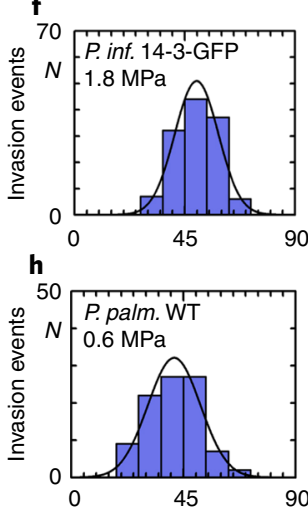

$\theta\left(^{\circ}\right)$

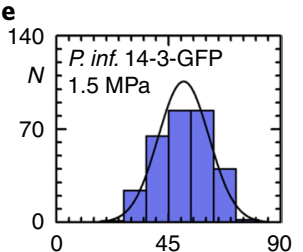

8

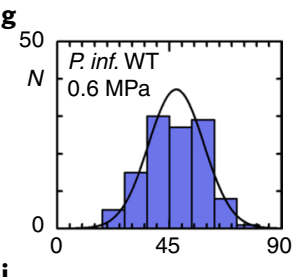

i

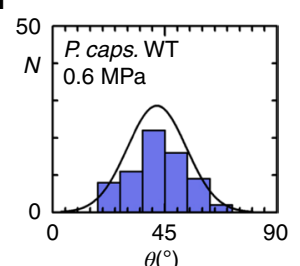

Fig. 1 | Phytophthora invades real and artificial hosts at an oblique angle without forming an appressorium. a, Two examples of the oblique angle of indentation and invasion of $P$. infestans 14-3-GFP on stems of potato plantlets ( $24 \mathrm{hpi}$ ) revealed by 3D confocal imaging (side view; GFP, green; host plastids, magenta; dotted line indicates the plant surface). b. Schematic illustration of host entry. Stage I: germination and non-invasive hyphal growth; stage II: substrate adherence and force application; stage III: surface fracture and invasion. c, Time series from confocal microscopy (side view) showing a single cyst ( $P$. infestans 14-3-GFP) germinating and invading an elastomeric surface at an oblique angle (dotted line indicates elastomer-medium interface; Supplementary Video 1). d-i, Angle of invasion for P. infestans ( $P$. inf.) 14-3-GFP (d-f), P. infestans WT (g), P. palmivora ( $P$. palm.) (h) and P. capsici ( . caps.) (i) at the indicated substrate elasticity (in MPa). Substrate entry occurs at an angle of invasion $\left(\theta, x\right.$-axis) centred at $41-51^{\circ}$ (Supplementary Table 3 ) and is independent of the substrate elasticity. $N$ ( $y$-axis) is the number of invasion events monitored in several independent experiments. Scale bars, $5 \mu \mathrm{m}$.

Naifu invasion. From fracture mechanics it is known that oblique indentation, also known as slicing, can facilitate surface fracture ${ }^{29}$ by localizing stresses at the surface and generating substantial tensile stresses. This effect is, for example, exploited in the single-bevel design of Japanese kitchen knives and guillotine blades to facilitate cutting. We hypothesize that Phytophthora spp. exploit hyphal slicing to invade their hosts without needing an appressorium. We call this the 'naifu' mechanism, after the Japanese word for knife. Our hypothesis leads to three testable predictions: (1) indentation leads to the propagation of a fracture along the direction of the applied force, which for oblique angles entails a crack that propagates ahead of the hypha; (2) to enable oblique application of force, unlike the radial symmetry observed in fungi, we should observe a polarized and non-concentric geometry of adhesion and indentation, lacking circular symmetry, that orients the force application vector; and (3) in turn, this is predicted to result in polarized surface deformations during pre-invasion (stage II) that are consistent with the angle of entry $\theta$ after invasion (stage III).

Molecular-fracture sensors. To visualize surface fracture, we incorporate the molecular mechanosensor spiropyran (Supplementary Figs. 3-7) into PDMS substrates. This sensor optically reveals mechanical damage by mechanochemical isomerization ${ }^{30,31}$ (Fig. 2a and Supplementary Fig. 2). Invasion of $P$. infestans into these fracture-reporting surfaces reveals the predicted scenario; approximately 10-20 min after the start of pressure application, a fluorescent crack propagates ahead of the germ tube (Fig. 2b, Extended Data Fig. 1 and Supplementary Video 3), in agreement with our hypothesis of oblique angles, into which the pathogen enters.

Quantifying surface mechanics. To measure the surface deformations induced by the indentation pressure applied by the hypha, we fluorescently label the substrates. We use three-dimensional (3D) imaging (Fig. 2c) to measure the intensity profile across the substrate-medium interface in each pixel. By fitting these intensity profiles normal to the surface to a sigmoidal function, we extract the surface height $\Delta h$ (Fig. $2 \mathrm{~d}$ ) with an axial resolution of approximately $50 \mathrm{~nm}$ (Fig. 2e). The resulting surface-deformation maps reveal a highly polarized mechanical geometry as predicted (Fig. 2f,g) that breaks the concentric circular symmetry expected for invasion using an appressorium as utilized by fungi. We observe distinct and spatially separated zones of adherence (upward deformations) and indentation (downward deformations), the amplitude of which grow over time until the surface fractures and the pathogen gains entry. These phenomena are similar for both $P$. infestans strains (14-3-GFP: Fig. 2f, Extended Data Fig. 2 and Supplementary Video 4; and wt: Extended Data Fig. 4 and Supplementary Video 6), P. palmivora wild type (WT) (Fig. 2g, Extended Data Fig. 3 and Supplementary Video 5) and P. capsici WT (Extended Data Fig. 5 and Supplementary Video 7). These results support our hypothesis and show that the naifu mechanism is conserved across Phytophthora. Cyst adhesion has no role in this process-we observe no adhesive (upward) deformations underneath the cysts (arrows in Extended Data Fig. 2). Moreover, invasion occurs only after substantial extension of hypha, which have an average length at invasion of $28 \pm 8 \mu \mathrm{m}$ and a minimum of $8 \mu \mathrm{m}$. This illustrates that the hypha itself is the invasion organ.

Mechanical equilibrium dictates that the indentation force $F_{\mathrm{i}}$, and adhesive force $F_{\mathrm{a}}$, are balanced. On this basis, we have developed a contact-mechanics model that describes naifu invasion (Fig. 3a). We model spatially separated, but mechanically coupled, adhesion and indentation sites onto which force is applied at an angle $\theta$, equal to the angle of-invasion (Fig. $1 \mathrm{c}-\mathrm{h}$ ). We reduce our data (Fig. 2f) to a line profile of surface deformation $\Delta h(t)$ for each 

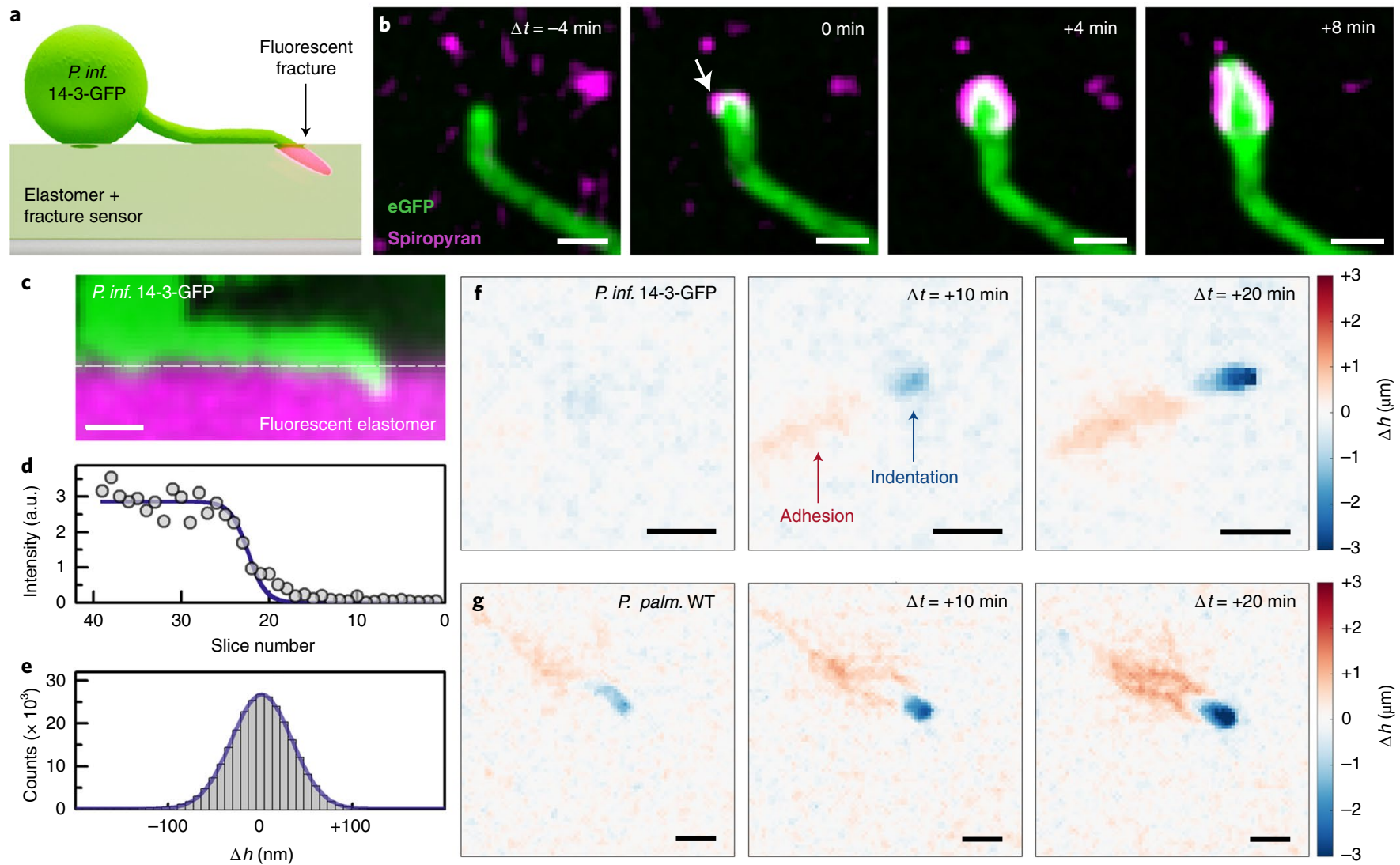

Fig. 2 | Visualizing the surface mechanics of artificial host entry by Phytophthora. a, Illustration of crack visualization using the fluorogenic mechanosensor spiropyran, which reports mechanical damage. b. Time-lapse recording of invasion by P. infestans 14-3-GFP (green) shows how a surface crack (magenta), visualized by mechanoactivation of spiropyran, grows ahead of the growing germ tube consistent with oblique pressure application (Supplementary Video 2), with $t=0$ defined as the moment of crack nucleation. The arrow indicates the nucleus of the surface crack. c, Confocal fluorescence image (side view) of a germ tube of $P$. infestans 14-3-GFP (green) indenting a fluorescent elastomer substrate. d. Example of an intensity profile (in arbitrary units, a.u.), measured in a single voxel, of substrate fluorescence in the $h$ direction (symbols) fitted to a sigmoidal function (solid line) to the substrate height $\Delta h$. e, The distribution of apparent height deviations of a flat elastomer substrate (grey bars) allows determination of the resolution in $\Delta h$ as the full-width at half-maximum of a Gaussian fit (solid line) at approximately $50 \mathrm{~nm} . \mathbf{f , g}$, Surface-deformation maps during invasion reveal the temporal increase in pressure application to induce fracture. Data reveal a polar mechanical geometry with separate adhesion and indentation sites, consistent with the naifu mechanism, for P. infestans 14-3-GFP (f) (Supplementary Video 3) and P. palmivora WT (g) (Supplementary Video 5). Scale bars, $5 \mu \mathrm{m}$.

time point. We find quantitative agreement between data and model in the pre-fracture stages of invasion (Fig. $3 b$ and Supplementary Video 8). This supports the notion that the polar invasion geometry emerges from the separation of an indentation site at the hyphal apex and a posterior site of adherence, separated by approximately $1-2 \mu \mathrm{m}$ (parameter $d$ in Supplementary Figs. 8 and 9). From these data, we compute the distribution of compressive and tensile stresses in the substrate (Fig. 3c), illustrating how oblique indentation localizes stresses towards the surface and gives rise to substantial tensile stresses (arrow in Fig. 3c) directed along the surface plane (Supplementary Fig. 10). We also note that the radius of curvature at the indentation site, reflected by parameter $a_{1}$ (Supplementary Figs. 8 and 9), is sharper than the average hyphal radius just posterior, hinting at morphological shaping of the apex to enhance stress localization. Combined, these effects lower the pressure required to induce a surface fracture ${ }^{29}$.

The magnitude of the invasive force $F_{\mathrm{i}}$ follows from this analysis. Initially, non-invasive hyphal growth occurs without detectable forces on the substrate (phase I; Fig. 3d). A switch to invasive growth leads to an increase of $F_{\mathrm{i}}$ (phase II). After fracture, hyphae grow into the substrate at relatively constant pressure to advance the crack (phase III). Additional examples are shown in Extended Data Fig. 6. Forces are in the range of several $\mu \mathrm{N}$, both for P. infestans (Fig. 3d) and for P. palmivora (Fig. 3e), and in agreement with forces reported for other pathogens $\mathrm{s}^{32-35}$. We calculate the maximum pressure generated at the hypha-substrate contact at the moment of fracture to be approximately $0.3 \mathrm{MPa}$.

Disrupting naifu invasion. Naifu invasion involves several key steps: polarized hyphal growth, substrate adherence and polar force application. To ascertain the requirement for each of these steps, we perform a series of experiments in which each is individually inhibited. As a measure for invasiness, we determine the percentage of hypha, counting only those with a length of at least $10 \mu \mathrm{m}$, that have successfully breached the substrate. As a reference, $P$. infestans wt, on untreated PDMS and in pure water, exhibits an invasion efficiency (IE) of $74 \pm 11 \%, 2 \mathrm{~h}$ post-inoculation (hpi) (Fig. $4 \mathrm{a}, \mathrm{b}, \mathrm{k}$ ).

First, we manipulate the cytoskeleton, as an orchestrator of cell polarity during tip growth of walled cells ${ }^{36-38}$, using latrunculin B (LatB), which inhibits actin polymerization ${ }^{39}$. A low dose $(0.1 \mu \mathrm{M})$ substantially reduces the IE to $34 \pm 10 \%$ (Fig. $4 \mathrm{k}$ ), whereas hyphal morphology is not affected (Fig. 4c,d); higher doses reduce IE further (Fig. 4k) and cause abnormal hyphal morphologies, as previously reported $^{39}$. Treatment with LatB also slows down non-invasive hyphal growth (Fig. 4l); invasive growth is halted completely at $1 \mu \mathrm{M}$ (Fig. 4k), while there is still finite non-invasive growth (Fig. 4l). 

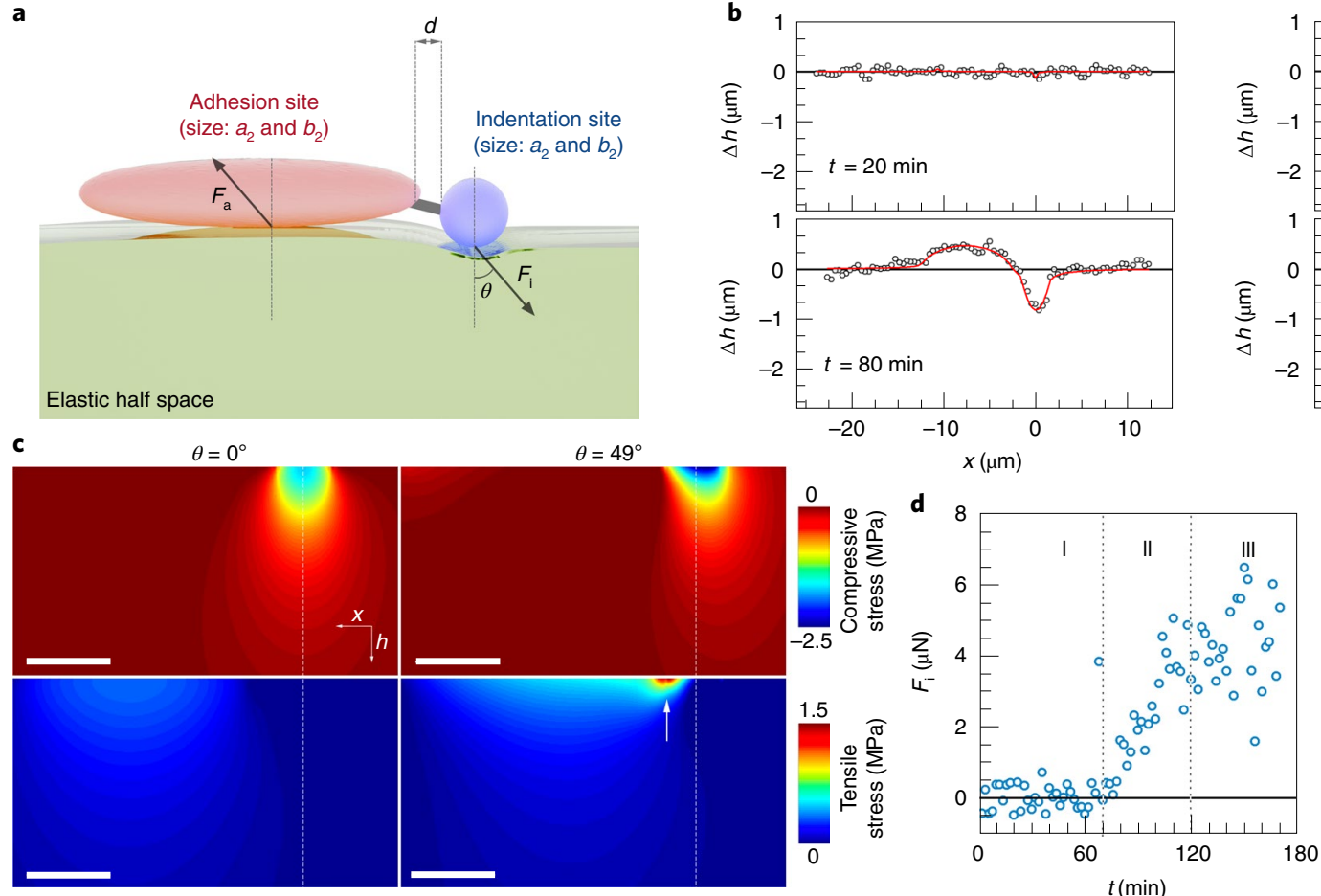
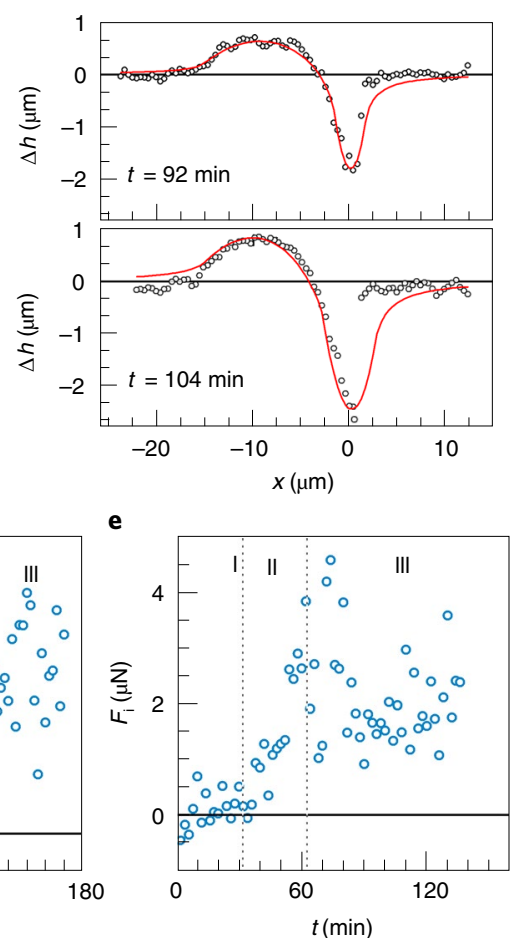

Fig. 3 | Quantitative surface mechanics reveal naifu mechanism. a, A linear-elastic contact-mechanics model for invasion by Phytophthora spp. b, Experimental surface-deformation profiles for P. infestans 14-3-GFP at various time points ( $t$ ) during invasion (open circles) and corresponding fits to the mechanical model (solid lines) (see also Supplementary Video 7). c, Predicted stress distributions in the $x h$-plane in the substrate (surface located at top, indentor located at dotted line) on the basis of experimentally determined parameters, for indentation normal to the substrate $\left(\theta=0^{\circ}\right)$ and under an oblique angle of $\theta=49^{\circ}$. Data show the maximal compressive and tensile stresses, taken as the maximum and minimum principal stress components. The arrow indicates a zone of tensile stress that emerges under oblique indentation. A full representation with all elements of the stress tensor is shown in Supplementary Information Fig. 10. d,e, Total indentation force $F_{\mathrm{i}}$ during invasion by $P$. infestans (d) and $P$. palmivora (e), obtained by fitting our model to experimental data, reveals three stages (see also Fig. 1a): a lag phase (I) followed by adherence and pressure application to induce fracture (II) and penetration into the substrate by crack growth (III). Scale bars, $5 \mu \mathrm{m}$.

This suggests an increased sensitivity to cytoskeletal disruption during invasion compared with non-invasive hyphal growth. In line with these observations, we observe that high doses of LatB also reduce infectivity on leaves ( $7 \mathrm{~d}$ post-inoculation (dpi); Extended Data Fig. 7). Clearly, actin is an essential coordinator of polarity both in non-invasive growth and in polar force generation during invasion, and thus crucial for naifu invasion.

Second, we suppress adhesion of hypha to the substrate, which is mediated by protein secretions ${ }^{40}$ and necessary to balance the indentation force. Adherence is a crucial element of pathogenicity in various plant pathogens $s^{16,41,42}$. We modify substrates with a poly(l-lysine)-graft-poly(ethylene glycol) (PLL-g-PEG) copolymer $^{43}$, which is known to suppress adhesion of a wide variety of biomolecules ${ }^{44,45}$. Adhesion suppression results in complete inhibition of invasion (Fig. 4k) without inhibiting hyphal growth (Fig. 4g,h,l). A similar non-adhesion treatment on leaves also results in a substantial reduction in infection efficiency at 7 dpi (Extended Data Fig. 7). These data confirm the necessity for strong host adherence in naifu invasion on both model substrates and real hosts.

Finally, we modulate the invasive pressure that Phytophthora can generate by increasing the osmotic pressure $\Pi$ of the medium ${ }^{14}$. Turgor generation is well-established to be a pre-requisite for pathogen invasion. We observe strong suppression of invasion efficiency at $\Pi>1.3 \mathrm{MPa}$ at $2 \mathrm{hpi}$ (Fig. $4 \mathrm{k}$ ). We also note that these high pressures lead to reduced growth rates (Fig. 4l) and a strong reduction in the germination efficiency (Fig. 4i,j). Generation of turgor is thus essential for invasion, with an estimated maximum turgor of between 1.3 and 2.8 MPa. This also illustrates that not all turgor is converted into pressure at the invasion site; the maximum invasion pressure of $0.3 \mathrm{MPa}$ is approximately $10-20 \%$ of the maximum turgor, in agreement with findings for the oomycete Pythium graminicola $^{46}$.

\section{Discussion}

Our data provide a picture of the mechanical strategy of host entry by Phytophthora. We find that these oomycetes invade hosts by a naifu mechanism, in which polar force application under an oblique angle facilitates surface failure and mediates host entry. We also show how cell polarization, substrate adherence and turgor generation are essential for naifu invasion. Despite the common use of the term appressorium when referring to a hyphal swelling at the point of host entry by Phytophthora spp., our observations of polar force application and the hypha itself as the invasion organ are incompatible with the definition of appressoriogenesis as involving a switch from polar to non-polar growth and the establishment of a new cell identity ${ }^{9}$. These findings warrant a critical reflection of the use of the term appressorium when describing oomycete invasion mechanisms. Moreover, the naifu mode of entry is in distinct contrast to the brute-force approach used by fungi ${ }^{12-15,32,47}$. As a consequence, fungicides that suppress force generation in fungi, for example, by targeting melanin-biosynthesis pathways, are not effective in controlling oomycetes. We have shown how Phytophthora invasion can be inhibited by cytoskeletal disruption or by blocking adhesion. These insights could lead to the identification of new targets in the search for effective control measures. 

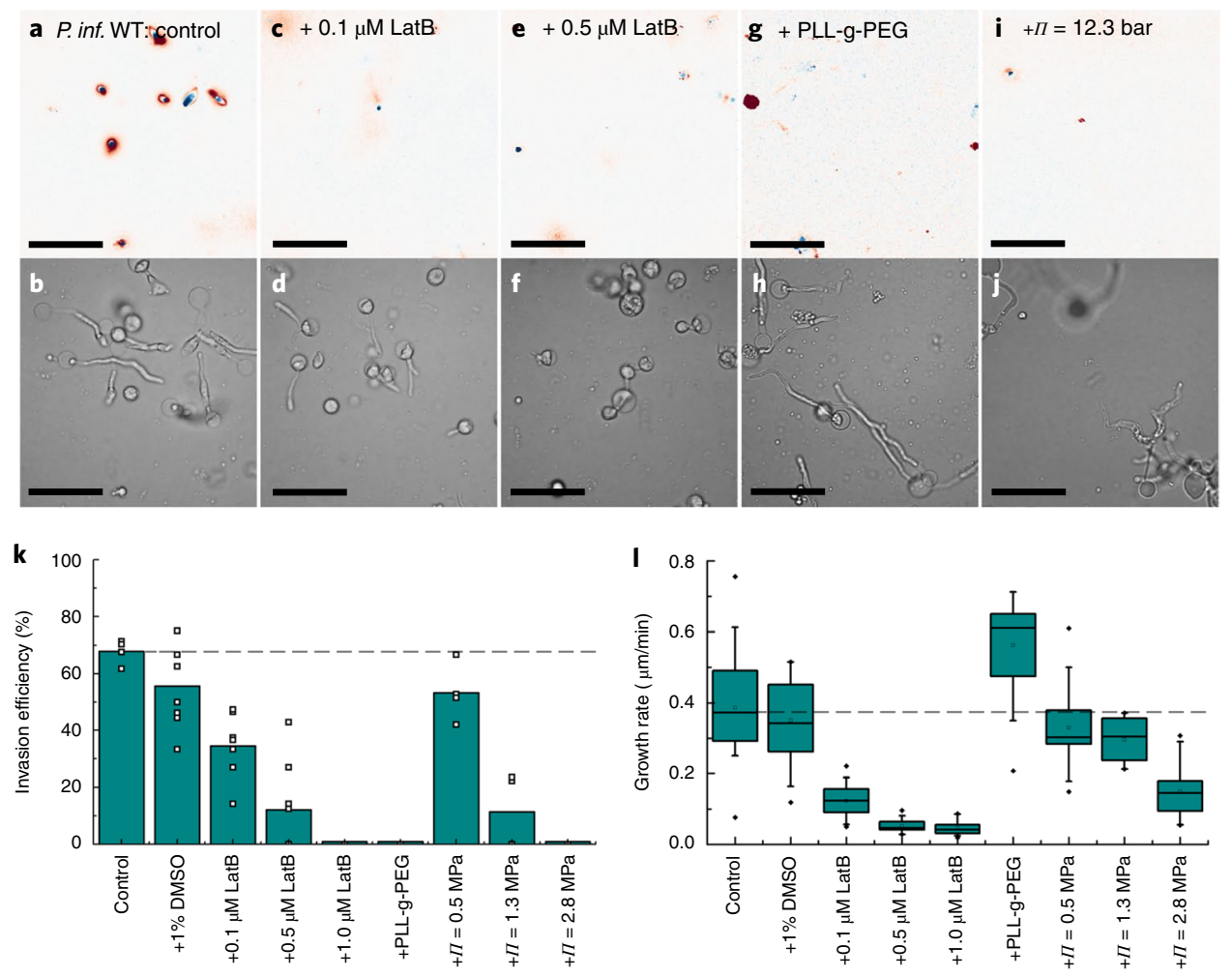

Fig. 4 | Polarized growth, substrate adherence and pressure generation are necessary for naifu-based host invasion. a-j, Surface-deformation profiles $(\mathbf{a}, \mathbf{c}, \mathbf{e}, \mathbf{g}, \mathbf{i}$; colour code as in Fig. 2b,c) and corresponding bright-field images $(\mathbf{b}, \mathbf{d}, \mathbf{f}, \mathbf{h}, \mathbf{j})$ of $P$. infestans WT invading PDMS surfaces, used to quantify invasion efficiency, subject to various treatments. Control $(\mathbf{a}, \mathbf{b})$, inhibition of actin polymerization with LatB $(\mathbf{c}-\mathbf{f})$, suppression of adhesion by coating PDMS with PLL-g-PEG copolymers $(\mathbf{g}, \mathbf{h})$ and inhibition of pressure generation by osmolyte treatment $(\mathbf{i}, \mathbf{j})$. Scale bars, $50 \mu \mathrm{m}$. $\mathbf{k}$, The effect of these treatments on invasion efficiency, defined as the percentage of hypha $>10 \mu \mathrm{m}$ that breach the surface at $2 \mathrm{hpi}$. Dashed grey line indicates the mean value of the control. I, Effect of the same treatments on the rate of hyphal extension during non-invasive growth. In box plots, the centre line is the median, black diamonds show 1st and 99th percentiles, box bounds delineate 25th and 75th percentiles, whiskers span 5th and 95th percentiles and the dotted line indicates the median of the control as reference.

\section{Methods}

Biological material. Phytophthora strains used in this study are P. infestans 14-3-GFP and WT (88069), P. palmivora WT (Pp6390) and P. capsici WT (BYA5). Details and growth conditions are described in the Supplementary Information and Supplementary Table 1. Potato (Solanum tuberosum) cultivar Bintje is propagated on tissue culture medium as described previously ${ }^{48}$. To obtain etiolated plantlets, in vitro grown plants are decapitated and placed in the dark for 2-4 weeks. Nicotiana benthamiana Cf-4 sobir1/sobir1-like $(\mathrm{Nb} \text {-sobir1 })^{49}$ plants are grown in soil in the greenhouse for 6 weeks and the youngest leaves $(>3 \mathrm{~cm}$ in diameter) are collected for detached-leaf assays.

In planta observations. Shoots from etiolated potato plantlets are cut in stem sections of $1 \mathrm{~cm}$ in length. These are stained in toluidine blue $\left(0.05 \mathrm{mg} \mathrm{ml}^{-1}\right.$ in $10 \mathrm{mM}$ HEPES, pH 7.4) for $30 \mathrm{~min}$, and subsequently rinsed 3 times in water. Each stem section is transferred to a well (Ibidi micro-Slide 8 well, uncoated) filled with $0.5 \mathrm{ml}$ of a $P$. infestans $14-3-\mathrm{GFP}$ zoospore suspension $\left(10^{5}\right.$ zoospores per $\left.\mathrm{ml}\right)$.

Then, $1 \mathrm{~mm}$ glass beads are added to the well to manoeuvre the stem section in the correct focal plane for imaging.

Artificial substrates. Elastomers are prepared by spin coating pre-mixed Sylgard 184 base:crosslinker mixtures in ratios 30:1 (0.6 MPa), 10:1 (1.5 MPa) and 5:1 $(1.8 \mathrm{MPa})$ onto cleaned no. 1 coverslips at $2,000 \mathrm{rpm}$, resulting in $33 \mu \mathrm{m}$ layers. The Young's modulus, the elastic constant for uniaxial tensile deformations, of the substrates is determined on a home-built indentation setup, described in detail elsewhere ${ }^{50}$ (Supplementary Fig. 1 and Supplementary Table 2). Cysts are loaded onto the surfaces in a $70 \mu \mathrm{l}$ droplet $\left(\sim 10^{5}\right.$ cells per $\left.\mathrm{ml}\right)$ and placed inside bespoke $3 \mathrm{D}$-printed sample chambers to minimize evaporation.

Confocal fluorescence microscopy. Three-dimensional confocal images are recorded on a Nikon C2 CSLM, equipped with a $\times 60,1.40 \mathrm{NA}$ immersion objective, at a resolution of $512 \times 512$ pixels $\left(212 \times 212 \mu \mathrm{m}^{2}\right)$ in the $x y$ plane and a $0.5 \mu \mathrm{m}$ step size in the axial $(z)$ direction, at a stack acquisition rate of $0.5 \mathrm{~min}^{-1}$. In all imaging experiments, we minimize the illumination intensity ( $2 \%$ of $15 \mathrm{~mW}$ at $488 \mathrm{~nm}$ and $4 \%$ at $15 \mathrm{~mW}$ at $561 \mathrm{~nm}$ ) as high light doses were found to inhibit germination and invasive growth. All confocal fluorescence images shown are false-coloured from greyscale raw data. Microscopy images shown in Fig. 1c and Extended Data Fig. $7 \mathrm{a}, \mathrm{b}$ are shown with a fire lookup table to improve visual contrast.

Image analysis. To detect the germ tube in image analysis, we threshold and binarize images recording either the cytosolic GFP channel (for P. infestans 14-3-GFP) or inverted images recorded on non-fluorescent WT species (P. infestans, P. palmivora and P. capsici) invading fluorescently tagged PDMS. In each $x y$ slice, the centroid of the germ tube is detected using the regionprops function in MatLab, from which the centroid contour of the germ tube can be reconstructed; the centroid contour is then used to determine the angle of invasion with respect to the substrate normal.

Molecular-fracture sensor. A functionalized spiropyran is used as a switch-on fluorescent fracture sensor. The molecule is synthesized by adapting the procedure of Davis et al. ${ }^{30}$ (Supplementary Information and Supplementary Figs. 2-6) and features two vinyl groups placed on opposite sides of the scissile spiro bond. This results in incorporation into the elastomer as a crosslinker during curing and ensures force transmission from the elastomer onto the mechanosensitive probe. We have validated that detection of merocyanine fluorescence emission is only due to mechanical activation by a control experiment using a spiropyran of the same chemical design that is not mechanically coupled to the PDMS network (Supplementary Fig. 7). After synthesis and purification, the dye is added to the uncured PDMS mixture at $10 \mathrm{mg}$ probe per g PDMS mixture. Preparation and characterization of the surfaces and imaging experiments are conducted as described above. Due to the low emission intensity of these fluorogenic probes, images shown in the main text are subjected to a Fourier-space bandpass treatment (lower threshold: 2 pixels, upper threshold 40 pixels, applied homogeneously to all images and between images) to suppress spurious single-pixel noise; examples of non-bandpass-filtered images are shown in Supplementary Fig. 11 for reference. 
Surface-deformation profiling. Fluorescent PDMS elastomer substrates are prepared by adding $15 \mu \mathrm{l}$ of a $2 \mathrm{mM}$ solution of Pyrromethene 650 (Exciton) in toluene for every gram of PDMS mixture. Substrates are spincoated as described above and prepared fresh before each experiment to minimize dye degradation during storage. Three-dimensional image stacks of the elastomer-water interface during pathogen invasion are recorded at a resolution of $0.41 \times 0.41 \times 0.5 \mu \mathrm{m}^{3}$ and an acquisition rate of $0.5 \mathrm{~min}^{-1}$. Image stacks are analysed in a custom MatLab routine to extract the surface profile; for each $x y$ pixel, the $z$-intensity profile of the Pyrromethene 650 channel is fitted to a sigmoidal function to obtain the local surface height with a determined sub-pixel resolution of $\sim 50 \mathrm{~nm}$ (Fig. 2e and Supplementary Information).

Mechanical model of invasion. We model the contact mechanics of invasion by a minimal linear-elastic model that describes the force balance between the indentation force applied by the pathogen and the force of adherence to the substrate. The forces generated by the pathogen are described as a Hertzian stress distribution $^{51}$ over two elliptical regions-with characteristic dimensions $a_{i}$ and $b_{i}$ (with subscript $i=1$ for indentation site and 2 for adhesion site) - which are spatially separated by a distance $d$, and mechanically coupled. The substrate is treated as a linear-elastic half space. In the calculations, the Poisson ratio of the elastomer is taken to be 0.45 , its modulus $0.58 \mathrm{MPa}$, as determined experimentally, and pressure is applied at an oblique angle of $49^{\circ}$. The model was fitted to the experimental data using the geometrical parameters and total indentation force $F_{i}$ as adjustable parameters, using a simulated-annealing algorithm, described in the Supplementary Information. The good agreement between model and experimental data breaks down once a surface-fracture nucleates, since fracture leads to non-linear deformations not captured by the linear-elastic model; however, by fitting the adhesive portion of the deformation profiles an estimate of the applied force can still be obtained during this final phase of the mechanical invasion.

Latrunculin B treatment. To perturb the organized actin cytoskeleton of pathogens during invasion, we follow the procedure established previously for $P$. infestans, which revealed a dose-dependent inhibition of germ tube growth upon exposure to the drug LatB, which suppresses actin polymerization ${ }^{39,52}$. LatB solubilized in DMSO is added to the zoospore suspension just before inoculation of the PDMS substrates to final concentrations of $0.1,0.5$ and $1.0 \mathrm{mM}$ LatB and $1 \mathrm{vol} \%$ DMSO, and, as a control, $1 \mathrm{vol} \%$ DMSO without LatB. We determine the invasion efficiency as the percentage of germinated cysts that have successfully fractured the artificial surface at $2 \mathrm{hpi}$. The hyphal growth rate is determined from the average germ tube length at $2 \mathrm{hpi}$ for all germinated cysts, both invasive and non-invasive, in the field of view.

Adhesion suppression. To observe the effect of adhesion on pathogen invasivity on PDMS substrates, we pre-treat the elastomeric surfaces with a PLL-g-PEG graft copolymer following established procedures ${ }^{43}$ known to suppress biomolecular adhesion and biofouling ${ }^{44,45}$. After spin coating and curing, PDMS surfaces are briefly exposed to an oxygen plasma followed by incubation in a $0.1 \mathrm{mg} \mathrm{ml}^{-1}$ solution of the PLL-g-PEG polymer (SuSoS Surface Technology, backbone PLL: $M_{\mathrm{w}}=24.7 \mathrm{~kg} \mathrm{~mol}^{-1}$, polydispersity index $=1.18$, PEG grafts: molecular mass $=2.2 \mathrm{~kg} \mathrm{~mol}^{-1}$, grafting ratio $=3.2$ ). After rinsing with deionized water, substrates are used to determine invasion efficiencies and hyphal growth rates as described above.

Osmotic counter pressure. We manipulate the maximum differential pressure between cell interior and exterior by adding PEG2000 as a calibrated osmolyte ${ }^{53}$, as was done previously for fungi ${ }^{14}$. Osmolyte is added to cysts from a stock solution to achieve osmotic pressures of $\Pi=0.5 \mathrm{MPa}$ (85 mM PEG2000), $1.3 \mathrm{MPa}(128 \mathrm{mM}$ PEG2000) and 2.8 MPa (170 mM PEG2000). The cyst-osmolyte mixtures are applied to fluorescent PDMS substrates and invasion efficiencies and hyphal growth rates are determined $2 \mathrm{hpi}$ as described above.

Infection assays. Detached leaves of $\mathrm{Nb}$-sobir1 plants are used to test the effects of LatB and surface adhesion on infection efficiency of $P$. infestans. Detached-leaf assays are performed as described ${ }^{54}$. Leaves are inoculated by applying $10 \mu \mathrm{l}$ droplets of a $P$. infestans WT zoospore suspension $\left(10^{5}\right.$ zoospores per $\mathrm{ml}$ ) onto the abaxial side. For LatB treatment, LatB dissolved in DMSO is added to the zoospore suspension. The final concentrations are 1 or $0.1 \mu \mathrm{M}$ LatB with $1 \%$ DMSO, and $1 \%$ DMSO without LatB and pure water as controls. For testing surface adhesion, a non-adhesive coating is sprayed on the abaxial side of the leaves prior to drop inoculation. The polymer, poly(ethylene glycol) methacrylate (PEGMA), was previously shown to suppress fungal pathogen adhesion to leaves ${ }^{55}$. It is similar to the PLL-g-PEG polymer described above, but instead of a cationic backbone (used for activated PDMS binding), PEGMA has a hydrophobic backbone and therefore binds better to the cuticle. PEGMA is prepared as described ${ }^{55}$. After spraying with a $10 \mathrm{wt} \%$ PEGMA solution in 80/20 water/isopropanol, the leaves are dried for $5 \mathrm{~min}$, rinsed with deionized water and inoculated. Infection efficiency is determined at $7 \mathrm{dpi}$ as the percentage of inoculated spots that show distinct lesions.
Statistics and reproducibility. We report the following sample sizes for the data presented in this article. Figure 1a: $n=15,5$ independent experiments; Fig. 1d: $n=200,8$ independent experiments; Fig. 1e: $n=303,3$ independent experiments; Fig. 1f: $n=126,2$ independent experiments; Fig. 1g: $n=115,2$ independent experiments; Fig. 1h: $n=94,2$ independent experiments; Fig. 1i: $N=68,3$ independent experiments.

Figure $2 \mathrm{~b}$ and Extended Data Fig. 1: $n=19,3$ independent experiments; Fig. $2 \mathrm{f}$ and Extended Data Fig. 2: $n=6,3$ independent experiments; Fig. $2 \mathrm{~g}$ and Extended Data Fig. 3: $n=7,3$ independent experiments; Extended Data Fig. 3: $n=6,4$ independent experiments; Extended Data Fig. 4: $n=8,4$ independent experiments; Fig. $3 \mathrm{~d}$ and Extended Data Fig. 6, for P. infestans: $n=3,3$ independent experiments, for P. palmivora: $n=2,2$ independent experiments; Fig. 4, control: $n=111,10$ fields of view, 2 independent experiments; $1 \%$ DMSO: $n=106,8$ fields of view, 2 independent experiments; $100 \mathrm{nM}$ LatB: $n=368,8$ fields of view, 2 independent experiments; $500 \mathrm{nM}$ LatB: $n=142$, 9 fields of view, 2 independent experiments; $1 \mathrm{mM}$ LatB: $n=153,8$ fields of view, 2 independent experiments; PEG-g-PLL: $n=74,16$ fields of view, 2 independent experiments; +5.0 bar osmotic pressure: $n=105$, 4 fields of view, 2 independent experiments; +13.2 bar osmotic pressure: $n=45$, 4 fields of view, 2 independent experiments; +27.8 bar osmotic pressure: $n=20$, 4 fields of view, 2 independent experiments; Extended Data Fig. 7, positive control LatB: $n=48$ leaves, 4 independent experiments; negative control: $n=20$ leaves, 1 independent experiment; $1 \%$ DMSO: $n=8$ leaves, 1 independent experiments; $100 \mathrm{nM}$ LatB: $n=20$ leaves, 3 independent experiments; $1 \mathrm{mM}$ LatB: $n=48$ leaves, 4 independent experiments; positive control PEGMA: $n=16$ leaves, 2 independent experiments; PEGMA coating: $n=16$ leaves, 2 independent experiments.

Reporting Summary. Further information on research design is available in the Nature Research Reporting Summary linked to this article.

\section{Data availability}

Raw data associated with the figures in this manuscript have been archived at https://doi.org/10.4121/14115461 and are publicly available at https://data.4tu. nl/articles/dataset/Data_underlying_the_publication_Phytophthora_pathogens_ exploit_slicing_action_for_host_invasion/14115461. Source data are provided with this paper.

\section{Code availability}

All data analysis algorithms used to perform the work presented in this manuscript were written by the authors using MatLab (v.2018b) and have been made publicly available at https://github.com/jorissprakel/Phytopthora_invasion.

Received: 12 December 2020; Accepted: 12 May 2021;

Published online: 01 July 2021

\section{References}

1. Fisher, M. C. et al. Emerging fungal threats to animal, plant and ecosystem health. Nature 484, 186-194 (2012).

2. Savary, S. et al. The global burden of pathogens and pests on major food crops. Nat. Ecol. Evol. 3, 430-439 (2019).

3. Haverkort, A. J., Struik, P. C., Visser, R. G. F. \& Jacobsen, E. Applied biotechnology to combat late blight in potato caused by Phytophthora infestans. Potato Res. 52, 249-264 (2009).

4. Haas, B. J. et al. Genome sequence and analysis of the Irish potato famine pathogen Phytophthora infestans. Nature 461, 393-398 (2009).

5. Kroon, L. P. N. M., Brouwer, H., de Cock, A. W. A. M. \& Govers, F. The genus Phytophthora anno 2012. Phytopathology 102, 348-364 (2012).

6. Kamoun, S. et al. The Top 10 oomycete pathogens in molecular plant pathology. Mol. Plant Pathol. 16, 413-434 (2015).

7. Bastmeyer, M., Deising, H. B. \& Bechinger, C. Force exertion in fungal infection. Annu Rev. Bioph Biom. 31, 321-341 (2002).

8. Latijnhouwers, M., de Wit, P. J. G. M. \& Govers, F. Oomycetes and fungi: similar weaponry to attack plants. Trends Microbiol. 11, 462-469 (2003).

9. Talbot, N. J. Appressoria. Curr. Biol. 29, R144-R146 (2019).

10. Nezhad, A. S. \& Geitmann, A. The cellular mechanics of an invasive lifestyle. J. Exp. Bot. 64, 4709-4728 (2013).

11. Foster, A. J. \& Talbot, N. J. Getting a grip on blast. Nat. Microbiol 5, 1457-1458 (2020).

12. Howard, R. J. \& Valent, B. Breaking and entering: host penetration by the fungal rice blast pathogen Magnaporthe grisea. Annu Rev. Microbiol. 50, 491-512 (1996).

13. Ryder, L. S. et al. A sensor kinase controls turgor-driven plant infection by the rice blast fungus. Nature 574, 423-427 (2019).

14. Howard, R. J., Ferrari, M. A., Roach, D. H. \& Money, N. P. Penetration of hard substrates by a fungus employing enormous turgor pressures. Proc. Natl Acad. Sci. USA 88, 11281-11284 (1991). 
15. Wilson, R. A. \& Talbot, N. J. Under pressure: investigating the biology of plant infection by Magnaporthe oryzae. Nat. Rev. Microbiol. 7, 185-195 (2009).

16. Rocha, R. O., Elowsky, C., Pham, N. T. T. \& Wilson, R. A. Spermine-mediated tight sealing of the Magnaporthe oryzae appressorial pore-rice leaf surface interface. Nat. Microbiol. 5, 1472-1480 (2020).

17. Chumley, F. G. Genetic analysis of melanin-deficient, nonpathogenic mutants of Magnaporthe grisea. Mol. Plant Microbe 3, 135 (1990).

18. Wang, T. et al. CgSCD1 is essential for melanin biosynthesis and pathogenicity of Colletotrichum gloeosporioides. Pathog. Basel Switz. 9, $141(2020)$.

19. Wheeler, M. H. \& Bell, A. A. Melanins and their importance in pathogenic fungi. Curr. Top. Med. Mycol. 2, 338-387 (1988).

20. Money, N. P., Davis, C. M. \& Ravishankar, J. P. Biomechanical evidence for convergent evolution of the invasive growth process among fungi and oomycete water molds. Fungal Genet. Biol. 41, 872-876 (2004).

21. Meng, S., Torto-Alalibo, T., Chibucos, M. C., Tyler, B. M. \& Dean, R. A. Common processes in pathogenesis by fungal and oomycete plant pathogens, described with Gene Ontology terms. BMC Microbiol. 9, S7 (2009).

22. Onoda, Y., Schieving, F. \& Anten, N. P. R. A novel method of measuring leaf epidermis and mesophyll stiffness shows the ubiquitous nature of the sandwich structure of leaf laminas in broad-leaved angiosperm species. J. Exp. Bot. 66, 2487-2499 (2015).

23. Gibson, L. J. The hierarchical structure and mechanics of plant materials. J. R. Soc. Interface 9, 2749-2766 (2012)

24. Whisson, S. C., Boevink, P. C., Wang, S. \& Birch, P. R. The cell biology of late blight disease. Curr. Opin. Microbiol. 34, 127-135 (2016).

25. Overdijk, E. J. R. et al. Interaction between the moss Physcomitrella patens and Phytophthora: a novel pathosystem for live-cell imaging of subcellular defence. J. Microsc. 263, 171-180 (2016).

26. Pieterse, C. M. J., Risseeuw, E. P. \& Davidse, L. C. An in planta induced gene of Phytophthora infestans codes for ubiquitin. Plant Mol. Biol. 17, 799-811 (1991).

27. Morris, B. M., Reid, B. \& Gow, N. A. R. Electrotaxis of zoospores of Phytophthora palmivora at physiologically relevant field strengths. Plant Cell Environ. 15, 645-653 (1992).

28. Miao, J. et al. Resistance assessment for oxathiapiprolin in Phytophthora capsici and the detection of a point mutation (G769W) in PcORP1 that confers resistance. Front. Microbiol. 7, 615 (2016).

29. Reyssat, E., Tallinen, T., Merrer, M. L. \& Mahadevan, L. Slicing softly with shear. Phys. Rev. Lett. 109, 244301 (2012).

30. Davis, D. A. et al. Force-induced activation of covalent bonds in mechanoresponsive polymeric materials. Nature 459, 68-72 (2009).

31. Celestine, A.-D. N. et al. Fracture-induced activation in mechanophorelinked, rubber toughened PMMA. Polymer 55, 4164-4171 (2014).

32. Bechinger, C. et al. Optical measurements of invasive forces exerted by appressoria of a plant pathogenic fungus. Science 285, 1896-1899 (1999).

33. Sun, Y., Tayagui, A., Shearer, H., Garrill, A. \& Nock, V. A microfluidic platform with integrated sensing pillars for protrusive force measurements on Neurospora crassa. In 2018 IEEE Micro Electro Mechanical Systems 1116-1119 (IEEE, 2018).

34. Money, N. P. in Biology of the Fungal Cell (eds Howard, R. J. \& Gow, N. A. R.) 237-249 (Springer, 2007).

35. Tayagui, A., Sun, Y., Collings, D. A., Garrill, A. \& Nock, V. An elastomeric micropillar platform for the study of protrusive forces in hyphal invasion. $L a b$ Chip 17, 3643-3653 (2017)

36. Heath, I. B. \& Steinberg, G. Mechanisms of hyphal tip growth: tube dwelling amebae revisited. Fungal Genet. Biol. 28, 79-93 (1999).

37. Harold, F. M. Force and compliance: rethinking morphogenesis in walled cells. Fungal Genet. Biol. 37, 271-282 (2002).

38. Gossot, O. \& Geitmann, A. Pollen tube growth: coping with mechanical obstacles involves the cytoskeleton. Planta 226, 405-416 (2007).

39. Ketelaar, T., Meijer, H. J. G., Spiekerman, M., Weide, R. \& Govers, F. Effects of latrunculin B on the actin cytoskeleton and hyphal growth in Phytophthora infestans. Fungal Genet. Biol. 49, 1014-1022 (2012).

40. Robold, A. V. \& Hardham, A. R. During attachment Phytophthora spores secrete proteins containing thrombospondin type 1 repeats. Curr. Genet. 47, 307-315 (2005).

41. Epstein, L. \& Nicholson, R. L. in Biological Adhesives (eds Smith, A. M. \& Callow, J. A.) 41-62 (Springer, 2006). https://doi.org/10.1007/978-3-54031049-5_3

42. Hardham, A. R. \& Shan, W. in Plant Relationships (ed. Deising, H. B.) 3-27 (2009).
43. Lee, S. \& Vörös, J. An aqueous-based surface modification of poly(dimethylsiloxane) with poly(ethylene glycol) to prevent biofouling. Langmuir 21, 11957-11962 (2005).

44. Heuberger, M., Drobek, T. \& Spencer, N. D. Interaction forces and morphology of a protein-resistant poly(ethylene glycol) layer. Biophys. J. 88, 495-504 (2005).

45. Marie, R., Beech, J. P., Vörös, J., Tegenfeldt, J. O. \& Höök, F. Use of PLL-g-PEG in micro-fluidic devices for localizing selective and specific protein binding. Langmuir 22, 10103-10108 (2006).

46. MacDonald, E., Millward, L., Ravishankar, J. P. \& Money, N. P. Biomechanical interaction between hyphae of two Pythium species (Oomycota) and host tissues. Fungal Genet. Biol. 37, 245-249 (2002).

47. Mendgen, K. \& Deising, H. Infection structures of fungal plant pathogens - a cytological and physiological evaluation. New Phytol. 124, 193-213 (1993).

48. Huang, S., Vleeshouwers, V. G. A. A., Visser, R. G. F. \& Jacobsen, E. An accurate in vitro assay for high-throughput disease testing of Phytophthora infestans in potato. Plant Dis. 89, 1263-1267 (2005).

49. Huang, W. R. H., Schol, C., Villanueva, S. L., Heidstra, R. \& Joosten, M. H. A J. Knocking out SOBIR1 in Nicotiana benthamiana abolishes functionality of transgenic receptor-like protein Cf-4. Plant Physiol. 185, kiaa047 (2020).

50. Boots, J. N. M., Fokkink, R., van der Gucht, J. \& Kodger, T. E. Development of a multi-position indentation setup: mapping soft and patternable heterogeneously crosslinked polymer networks. Rev. Sci. Instrum. $\mathbf{9 0}$, 015108 (2019).

51. Johnson, K. L. Contact Mechanics (Cambridge Univ. Press, 1985)

52. Kots, K., Meijer, H. J. G., Bouwmeester, K., Govers, F. \& Ketelaar, T. Filamentous actin accumulates during plant cell penetration and cell wall plug formation in Phytophthora infestans. Cell Mol. Life Sci. 74, 909-920 (2016).

53. Money, N. P. Osmotic pressure of aqueous polyethylene glycols: relationship between molecular weight and vapor pressure deficit. Plant Physiol. 91, 766-769 (1989).

54. Vleeshouwers, V. G. A. A. et al. A laboratory assay for Phytophthora infestans resistance in various solanum species reflects the field situation. Eur. J. Plant Pathol. 105, 241-250 (1999).

55. Vallieres, C. et al. Discovery of (meth)acrylate polymers that resist colonization by fungi associated with pathogenesis and biodeterioration. Sci. Adv. 6, eaba6574 (2020).

\section{Acknowledgements}

This research is supported by research programme ECHO with project number 712.016.001, financed by the Dutch Research Council (NWO) (to J. Bronkhorst and J.S.); NWO Science domain (NWO-ENW) project GSGT.GSGT.2018.024 (to M.K.); and the European Research Council (ERC) project CoG-SOFTBREAK (to J.v.d.G). We thank V. Vleeshouwers (WUR Plant Breeding) for supplying seedlings.

\section{Author contributions}

J. Bronkhorst, T.K., F.G. and J.S. conceived and designed the project. J. Bronkhorst, M.K., S.v.V., J.M.C. and K.K. performed experimental work. J. Bronkhorst, S.v.V., J. Buijs and J.S. conceived image analysis routines and performed the analysis. J. Bronkhorst, J.v.d.G. and J.S. performed mathematical modelling. J. Bronkhorst, T.K., F.G. and J.S. wrote the paper with assistance and input of all coauthors.

\section{Competing interests}

The authors declare no competing interests.

\section{Additional information}

Extended data is available for this paper at https://doi.org/10.1038/s41564-021-00919-7.

Supplementary information The online version contains supplementary material available at https://doi.org/10.1038/s41564-021-00919-7.

Correspondence and requests for materials should be addressed to J.S.

Peer review information Nature Microbiology thanks Nicholas Money, Richard Wilson and the other, anonymous, reviewer(s) for their contribution to the peer review of this work. Peer reviewer reports are available.

Reprints and permissions information is available at www.nature.com/reprints.

Publisher's note Springer Nature remains neutral with regard to jurisdictional claims in published maps and institutional affiliations.

(c) The Author(s), under exclusive licence to Springer Nature Limited 2021 

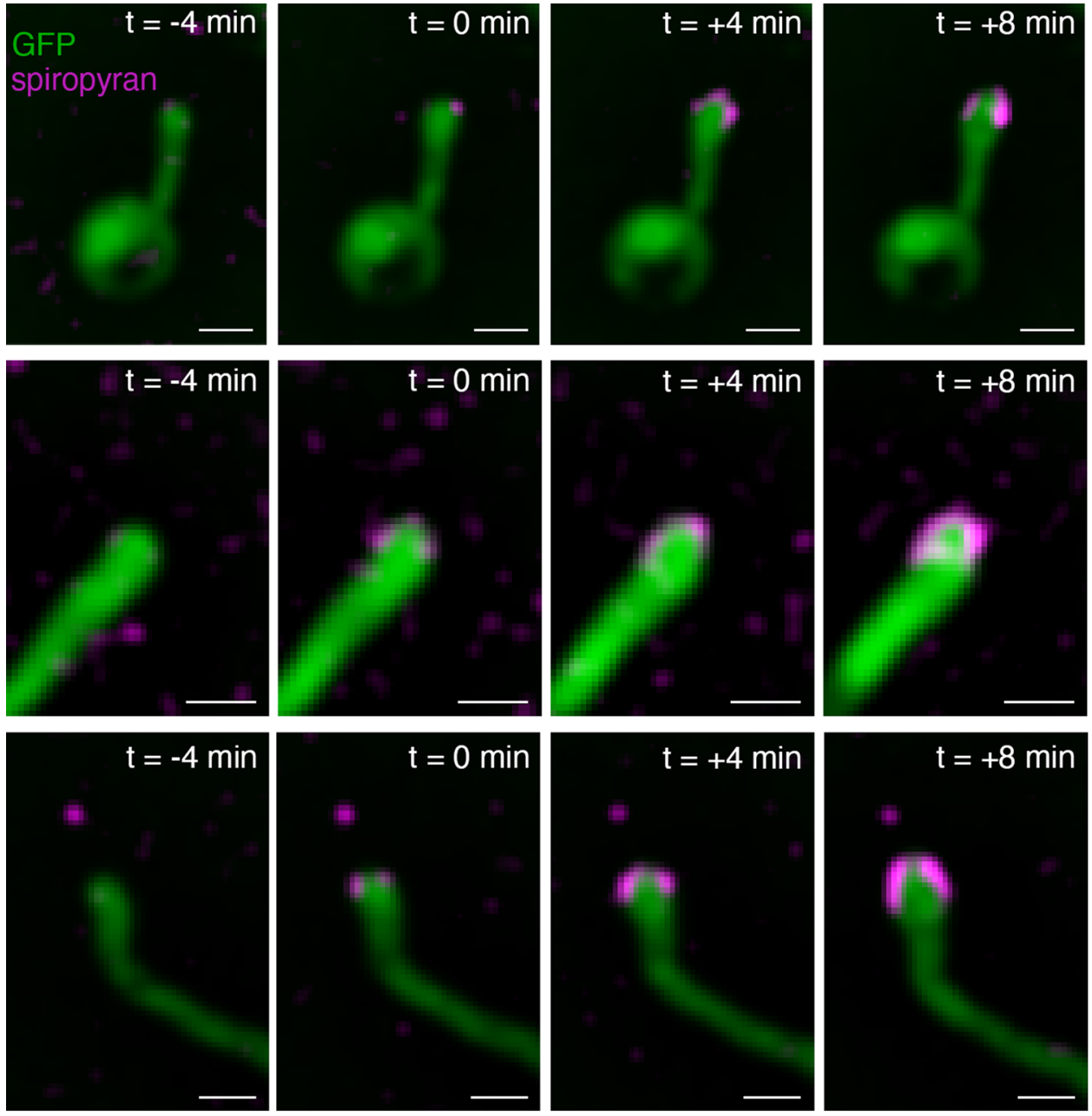

Extended Data Fig. 1 | Spiropyran fracture sensor reveals locus of surface invasion by the pathogen. Additional examples of time series that reveal the time and locus of crack nucleation by invasion of $P$. infestans - 14:3 eGFP into a force-sensor elastomer substrate. We define $t=0$ min as the moment of crack nucleation. All scale bars represent $5 \mu \mathrm{m}$. 
a

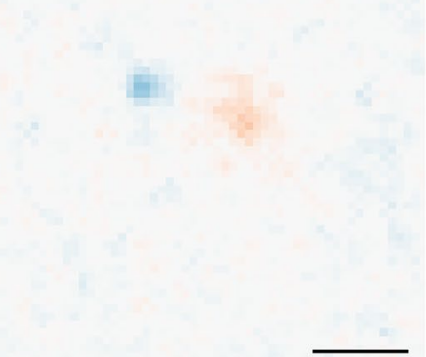

b

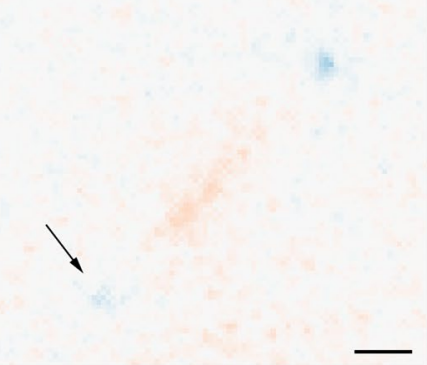

$\Delta t=+10 \mathrm{~min}$

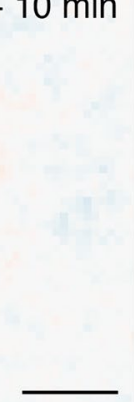

$\Delta t=+10 \min$

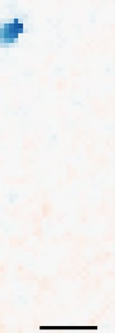

$\Delta t=+20 \mathrm{~min}$

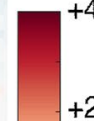

$+2$

字

0 产

क्

$-2$

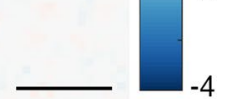

$\Delta t=+20 \min$

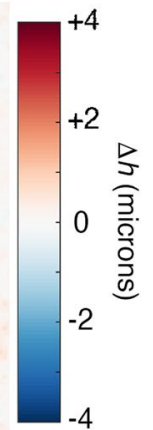

Extended Data Fig. 2 | Additional time series of surface deformations during invasion of elastomer substrates by P. infestans - 14:3 eGFP. Colors indicate surface deformations in micrometers. Red: positive deformations due to adhesion; blue: negative deformations due to indentation. Arrows in $b$ point to the location of the cyst, showing weak indentation but no adhesion. Scale bars: $5 \mu \mathrm{m}$. 
a

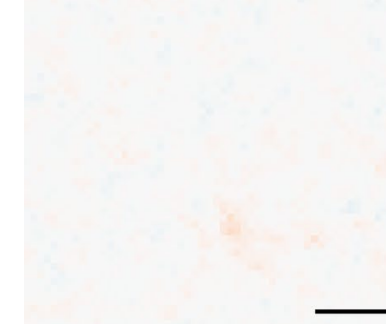

b

b
$\Delta t=+10 \mathrm{~min}$

$$
\Delta t=+20 \min
$$

II

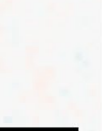

$\Delta t=+10 \mathrm{~min}$

$\Delta t=+20 \min$
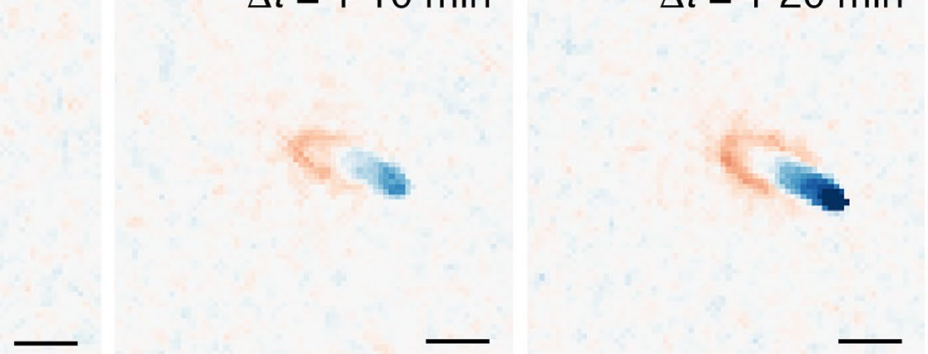

$\Delta t=+30 \mathrm{~min}$
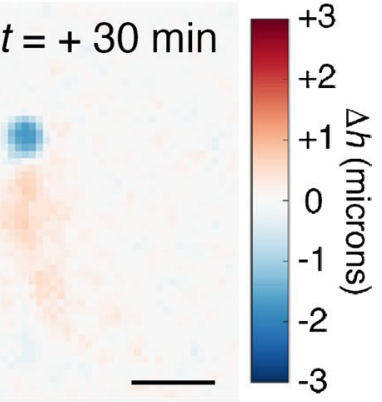

$\Delta t=+30 \mathrm{~min}$

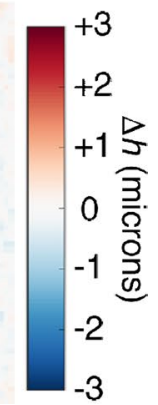

Extended Data Fig. 3 | Additional time series of surface deformations during invasion by P. palmivora - wt. Colors indicate surface deformations in micrometers. Red: positive deformations due to adhesion, blue: negative deformations due to indentation. Scale bars: $5 \mu \mathrm{m}$. 
a

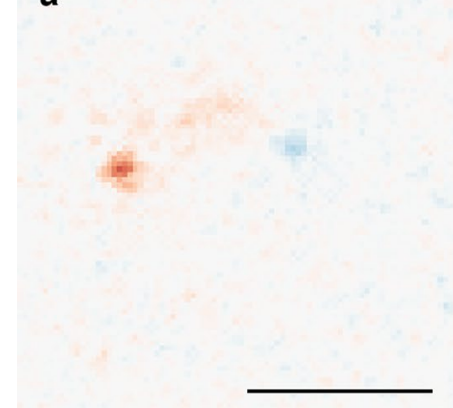

b

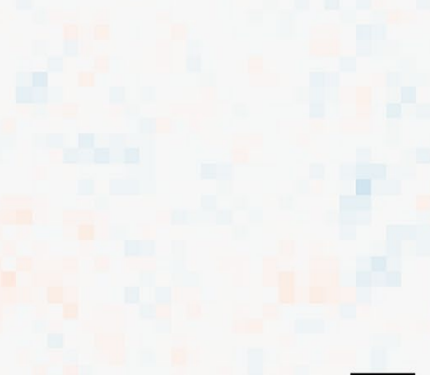

c

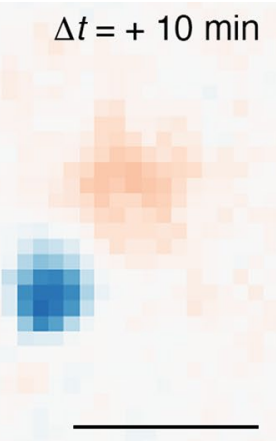

$$
\Delta t=+10 \min
$$
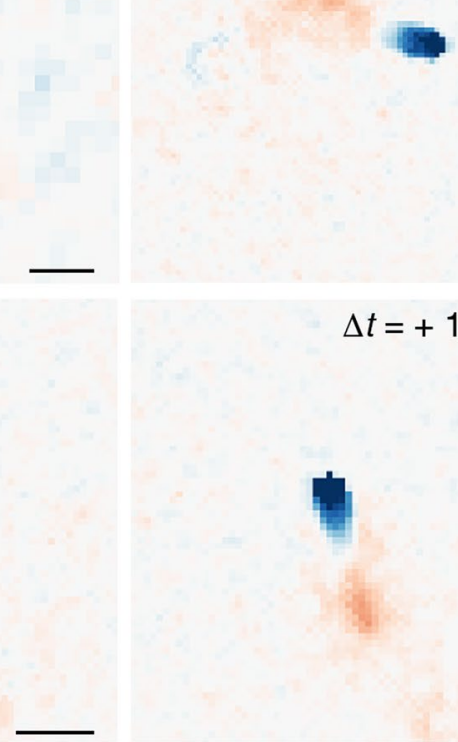

$\Delta t=+10 \min$
$\Delta t=+10 \min$

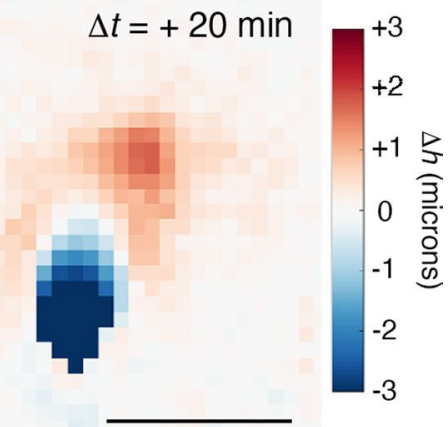

$$
\Delta t=+20 \min
$$

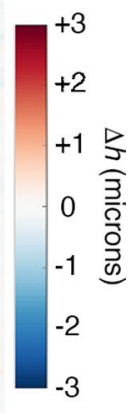

$$
\Delta t=+20 \min
$$

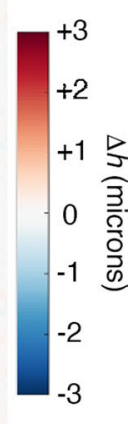

Extended Data Fig. 4 | Time series of surface deformations during invasion on elastomer substrates by P. infestans - wt. Colors indicate surface deformations in micrometers. Red: positive deformations due to adhesion, Blue: negative deformations due to indentation. Scale bars: $5 \mu \mathrm{m}$. 
a

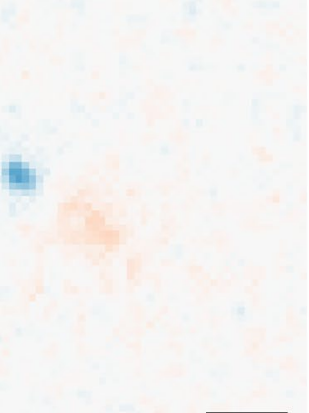

b

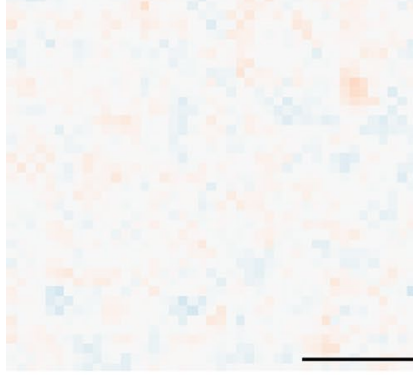

C

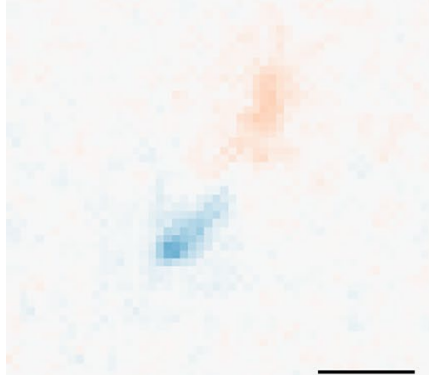

$$
\Delta t=+10 \min
$$

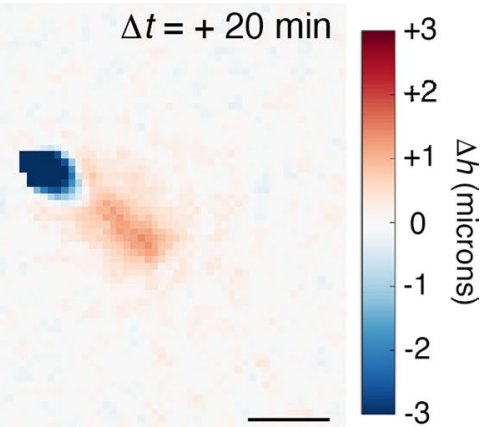

$\Delta t=+10 \min$

$\Delta t=+20 \mathrm{~min}$

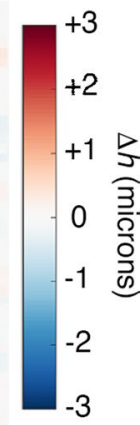

$$
\Delta t=+10 \min
$$

$$
\Delta t=+20 \mathrm{~min}
$$

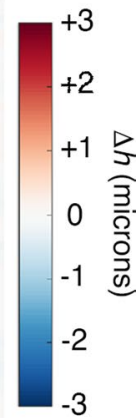

Extended Data Fig. 5 | Time series of surface deformations pathogenic invasion on elastomer substrates by P. capsici - wt. Colors indicate surface deformations in micrometers. Red: positive deformations due to adhesion, blue: negative deformations due to indentation. Scale bars: $5 \mu \mathrm{m}$. 


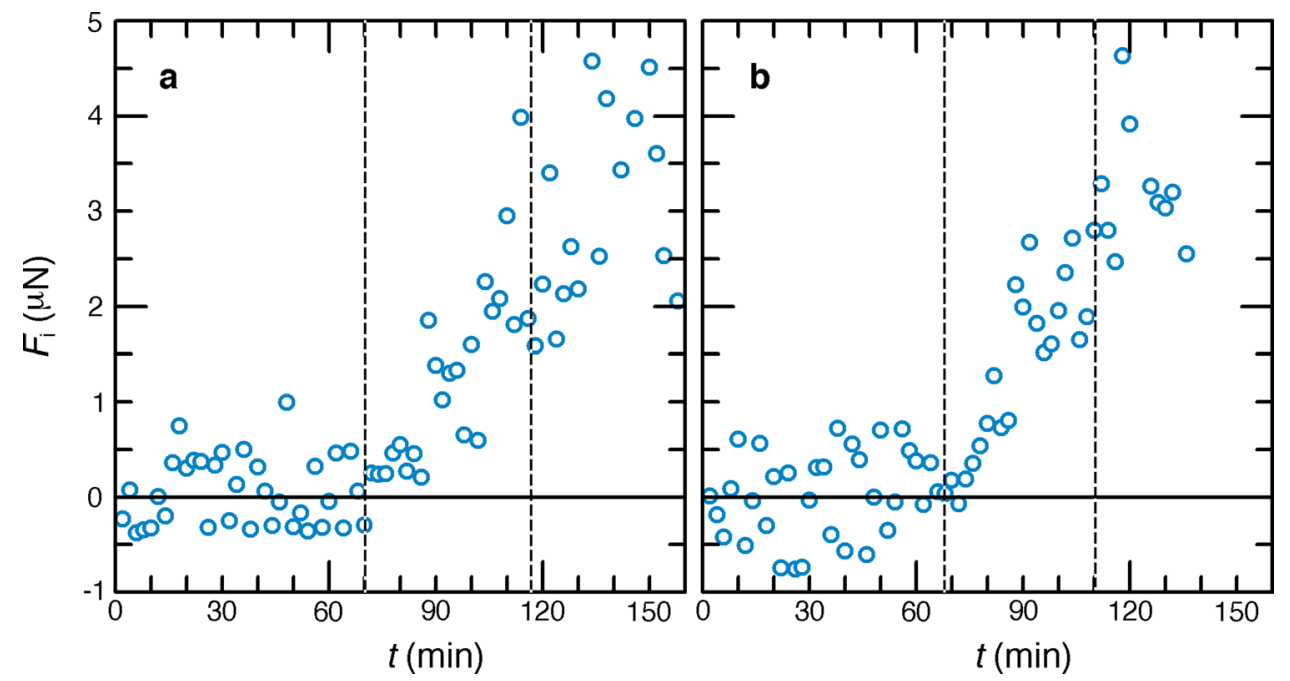

Extended Data Fig. 6 | Mechanical invasion exhibits three stages. Two additional examples of total indentation force $F_{\mathrm{i}}$ as a function of time ( $\mathrm{t}$ ) for the mechanical invasion of $P$. infestans - 14:3 eGFP into 0.58 MPa elastomer substrates, exhibiting three temporal stages (see Fig. 1a): I) germ tube growth is observed but no detectable surface deformations occur, II) pressure application increases until a fracture nucleates, III) pathogen invades into the crack opening, during which the crack propagates at relatively constant force. 
a

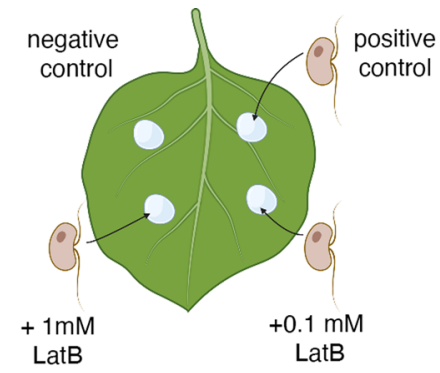

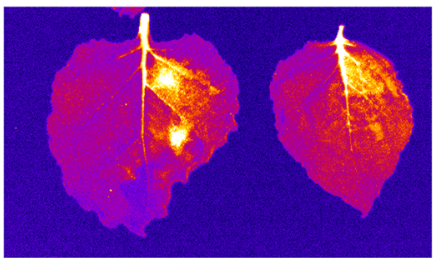
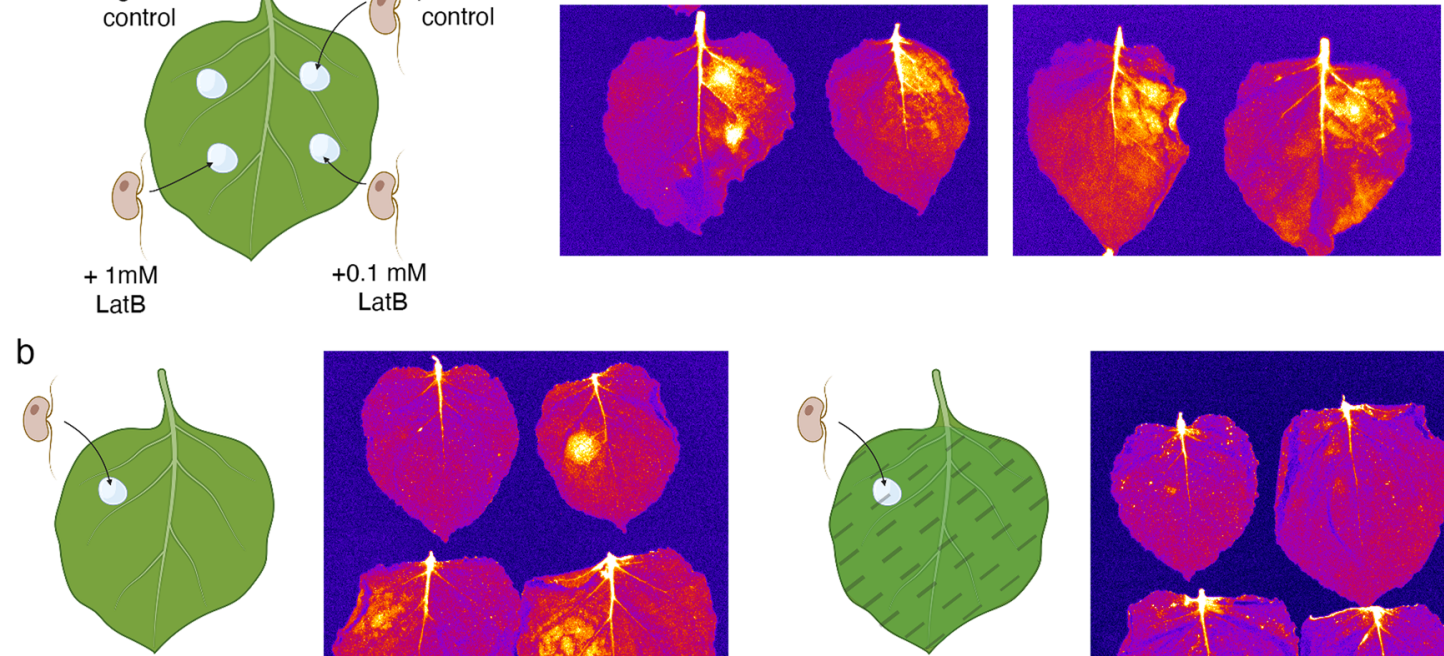

positive control

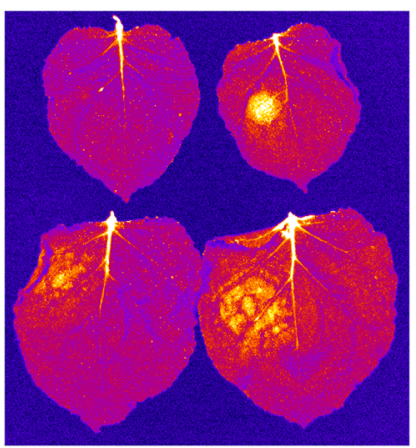

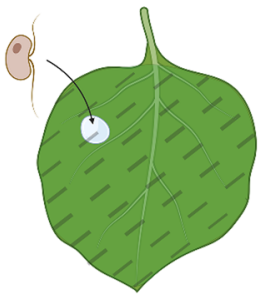

PEGMA coated
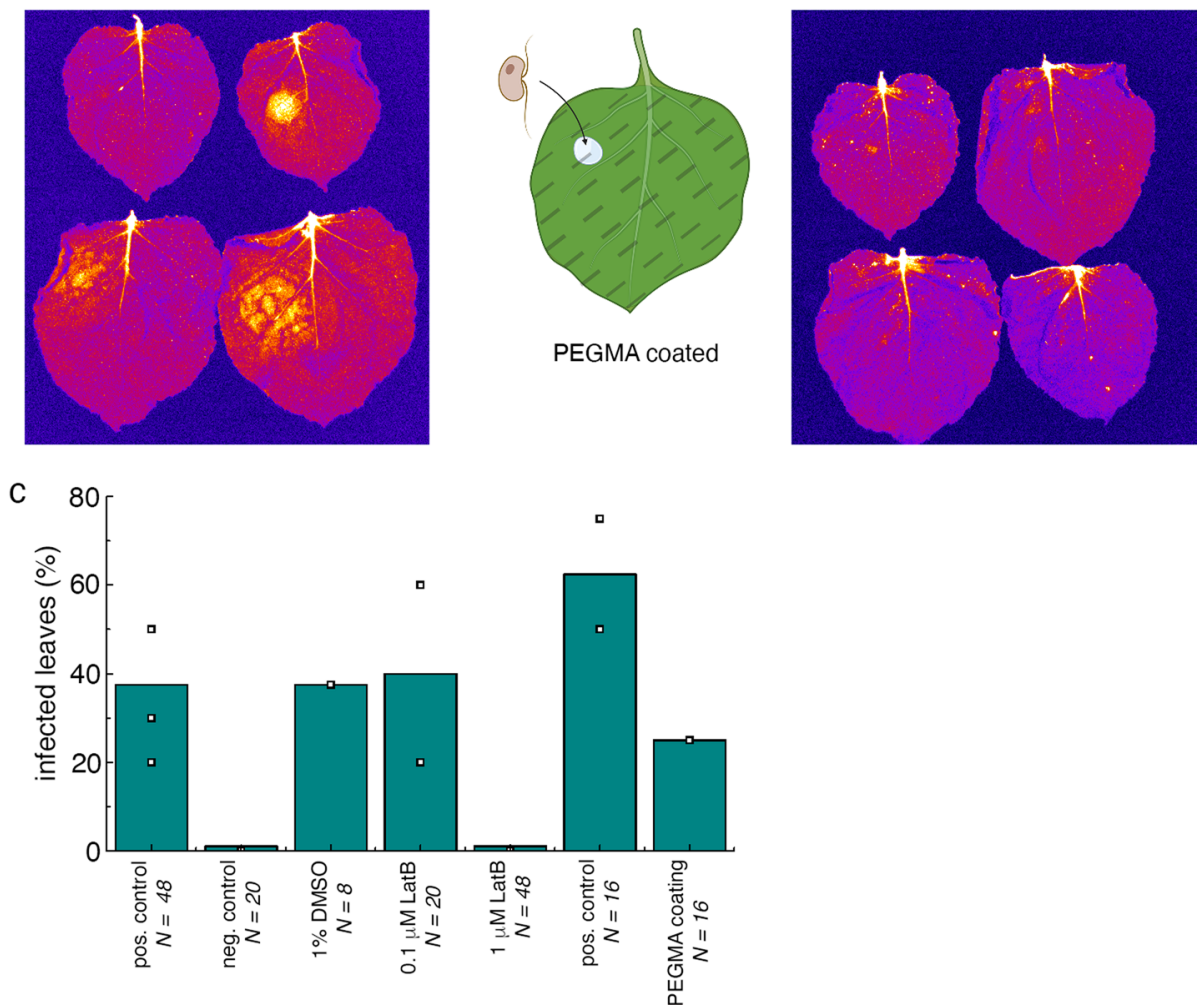

Extended Data Fig. 7 | Leaf infection assays. a, Detached leaf assay to test the effect of cytoskeletal disruption with LatB on P.inf-wt infectivity on $\mathrm{Nb}$-sobir1 leaves. b. Detached leaf assay to test the effect of a non-adhesion coating on P.inf-wt infectivity on Nb-sobir leaves. Leaf images are deep-red images that reveal lesions as bright orange-white zones (a-b). Schematic illustrations created with BioRender.com. c, Infectivity, determined as the percentage of inoculated spots that show a clear lesion $7 \mathrm{dpi}$, for various controls and treatments, showing clear reduction in pathogenicity for high LatB concentrations and the non-adhesion coating. Numbers $N$ indicate the total number of leaves tested for each sample. 


\section{Reporting Summary}

Nature Research wishes to improve the reproducibility of the work that we publish. This form provides structure for consistency and transparency in reporting. For further information on Nature Research policies, see our Editorial Policies and the Editorial Policy Checklist.

\section{Statistics}

For all statistical analyses, confirm that the following items are present in the figure legend, table legend, main text, or Methods section.

n/a Confirmed

$\square$ The exact sample size $(n)$ for each experimental group/condition, given as a discrete number and unit of measurement

$\square$ \A statement on whether measurements were taken from distinct samples or whether the same sample was measured repeatedly

$\triangle$ The statistical test(s) used AND whether they are one- or two-sided

$\square$ Only common tests should be described solely by name; describe more complex techniques in the Methods section.

Х $\square$ A description of all covariates tested

$\square$ \ A description of any assumptions or corrections, such as tests of normality and adjustment for multiple comparisons

$\square$ A full description of the statistical parameters including central tendency (e.g. means) or other basic estimates (e.g. regression coefficient)

$\triangle$ AND variation (e.g. standard deviation) or associated estimates of uncertainty (e.g. confidence intervals)

Х For null hypothesis testing, the test statistic (e.g. $F, t, r$ ) with confidence intervals, effect sizes, degrees of freedom and $P$ value noted

Wive $P$ values as exact values whenever suitable.

Х $\square$ For Bayesian analysis, information on the choice of priors and Markov chain Monte Carlo settings

Х $\square$ For hierarchical and complex designs, identification of the appropriate level for tests and full reporting of outcomes

Х $\square$ Estimates of effect sizes (e.g. Cohen's $d$, Pearson's $r$ ), indicating how they were calculated

Our web collection on statistics for biologists contains articles on many of the points above.

\section{Software and code}

Policy information about availability of computer code

Data collection Microscopy data: Nikon NIS-Elements AR 5.21.03), NMR: Bruker TopSpin 3.5 PL 6, Indentation measurements: home-written code in MatLab $2018 b$

Data analysis All data analysis was performed using home-written code in MatLab 2018b; these are available on the GitHub repository: https:/github.com/ jorissprakel/Phytopthora_invasion

For manuscripts utilizing custom algorithms or software that are central to the research but not yet described in published literature, software must be made available to editors and reviewers. We strongly encourage code deposition in a community repository (e.g. GitHub). See the Nature Research guidelines for submitting code \& software for further information.

\section{Data}

Policy information about availability of data

All manuscripts must include a data availability statement. This statement should provide the following information, where applicable:

- Accession codes, unique identifiers, or web links for publicly available datasets

- A list of figures that have associated raw data

- A description of any restrictions on data availability

The datasets generated during and/or analyzed during the current study are available from the corresponding author on reasonable request. All raw data associated with figures in this manuscript, and its Supplemental Information, have been archived at URL: https://data.4tu.nl/articles/dataset/

Data_underlying_the_publication_Phytophthora_pathogens_exploit_slicing_action_for_host_invasion/14115461 


\section{Field-specific reporting}

Please select the one below that is the best fit for your research. If you are not sure, read the appropriate sections before making your selection. $\bigotimes$ Life sciences $\quad \square$ Behavioural \& social sciences $\square$ Ecological, evolutionary \& environmental sciences

For a reference copy of the document with all sections, see nature.com/documents/nr-reporting-summary-flat.pdf

\section{Life sciences study design}

All studies must disclose on these points even when the disclosure is negative.

Sample size

Sample sizes were chosen according to common standards in the field. For each experiment at least a duplicate, and in most cases many more, was performed in independent experiments, performed on different days, to minimize day-to-day variations in the organism response. Moreover, all experiments were conducted on at least two different species from the Phytophthora genus, to verify the absence of speciesspecific variations. For experiments in which results where discussed in a quantitative sense (e.g. measurement of averages of angle of invasion, invasion efficiency) $\mathrm{N}$ was in many cases $>100$, with the exception of in-planta studies, where samples sizes where at least $\mathrm{N}=15$ due to the increased experimental effort involved in performing these assays. All sample sizes for data presented in this manuscript are reported in the Table of Experimental Details in the Supplementary Information file.

Data exclusions

Replication

Randomization

Blinding
No data was excluded from the analysis or representation

All experiments were repeated at least in duplicate independent experiments, which in all cases provided a consistent result.

No subdivision of cells into groups was involved in our experiment, so randomization was not applicable to our experimental design.

No organisms with a consiouscness where included in this study, so blinding was not applicable to our experimental design.

\section{Reporting for specific materials, systems and methods}

We require information from authors about some types of materials, experimental systems and methods used in many studies. Here, indicate whether each material, system or method listed is relevant to your study. If you are not sure if a list item applies to your research, read the appropriate section before selecting a response.

\begin{tabular}{|c|c|}
\hline $\mathrm{n} / \mathrm{a}$ & Involved in the study \\
\hline Х & $\square$ Antibodies \\
\hline$\bigotimes$ & $\square$ Eukaryotic cell lines \\
\hline$\bigotimes$ & $\square$ Palaeontology and archaeology \\
\hline$\bigotimes$ & $\square$ Animals and other organisms \\
\hline 邓 & $\square$ Human research participants \\
\hline Х & $\square$ Clinical data \\
\hline$凶$ & $\square$ Dual use research of concern \\
\hline
\end{tabular}

\begin{tabular}{l|l}
\multicolumn{2}{l}{ Methods } \\
\hline n/a & Involved in the study \\
$\bigotimes$ & $\square$ ChIP-seq \\
$\square$ & $\square$ Flow cytometry \\
$\square$ & $\square$ MRI-based neuroimaging
\end{tabular}

